\title{
Good News on Research Integrity and Publication Ethics
}

\author{
Rosemary S. Shinkai
}

Editor-in-chief

$\mathrm{I}$ is a great pleasure to publish in this issue the guest editorial by Dr. Sonia Vasconcelos, faculty member at the Science Education Program/Medical Biochemistry Institute, Federal University of Rio de Janeiro, UFRJ, Brazil. Sonia was the general co-ordinator of the first and second Brazilian Meeting on Research Integrity, Science, and Publication Ethics, held in several Brazilian cities in 2010 and 2012, respectively. She has produced some of the most important studies and papers on these subjects since her doctoral studies, being a key Brazilian scholar engaged in educational and research to promote good practices among young investigators. In her editorial, Sonia presents a brief background of the work undergoing at present through a network connecting several parties in Brazil and abroad.

One of the immediate outcomes of these efforts is the Joint Statement of the II Brazilian Meeting on Research Integrity, Science and Publication Ethics (II BRISPE) May 28-June 1, 2012. We are also proud to publish here the English and Portuguese versions of this Joint Statement, which is primarily available at the BRISPE website along with the material discussed in the three venues in the cities of Rio de Janeiro, São Paulo and Porto Alegre. The scope of this event was to promote a forum where researchers, editors, educators, students, and policymakers could jointly learn how to face current challenges for prevention, management, and punishment of misconduct in our country.

Another source of information and training will be the First Seminar of the Committee on Publication Ethics (COPE) to be held during the annual meeting of the Brazilian Association of Scientific Editors (ABEC) in Florianópolis, SC, Brazil, on November $12^{\text {th }}, 2012$. It will be a great opportunity to learn with COPE council members and guest speakers about the international standards of editorial good practices. This seminar is designed with short lectures and discussion of cases to help editorial members to manage difficult situations involving misconduct, correction of the published literature (for example, by means of retraction of papers), interaction between journals and institutions, and editorial policies and guidelines.

\section{Websites of interest:}

- Brazilian Meeting on Research Integrity, Science and Publication Ethics (BRISPE)

- CAPES - Combate ao Plágio

- $\mathrm{CNPq}$ - Comissão de Integridade na Atividade Científica

- COPE (Committee on Publication Ethics)

- FAPESP - Boas Práticas Científicas

- First World Conference on Research Integrity (Lisbon 2007)

- ORI (US Office of Research Integrity)

- Second World Conference on Research Integrity (Singapore, 2010) 